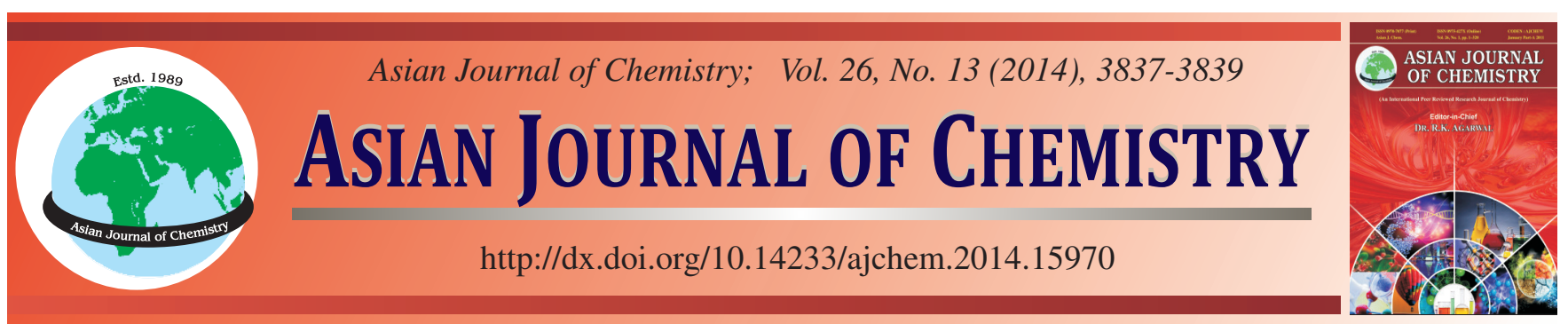

\title{
Characterization of $\mathrm{SiO}_{2}-\mathrm{TiO}_{2}$ and Photocatalytic Degradation of Methyl Orange
}

\author{
Lina Zhou ${ }^{1}$, Xiaofang Han ${ }^{1}$, Wenjie Zhang ${ }^{1, *}$ and Hongbo HE ${ }^{2, *}$
}

${ }^{1}$ School of Environmental and Chemical Engineering, Shenyang Ligong University, Shenyang 110159, P.R. China

${ }^{2}$ Institute of Applied Ecology, The Chinese Academy of Sciences, Shenyang 110016, P.R. China

*Corresponding authors: Tel: +86 24 24680345; E-mail: wjzhang@aliyun.com; hehongbo@iae.ac.cn

\begin{abstract}
A SiO $2-\mathrm{TiO}_{2}$ composite photocatalyst was prepared through sol-gel method for photocatalytic degradation of methyl orange. The material is composed of anatase $\mathrm{TiO}_{2}$ and most probably amorphous $\mathrm{SiO}_{2}$. The crystallite size of the $\mathrm{TiO}_{2}(101)$ plane is $14.39 \mathrm{~nm}$. The surface of the sample is fairly rough. Some particles in the size smaller than $1000 \mathrm{~nm}$ scatter on the surface. The pore size of the material is mainly below $15 \mathrm{~nm}$ and the pore diameter mainly distributes in the range from $2 \mathrm{~nm}$ to $11 \mathrm{~nm}$. Adsorption only contributes a small part, less than $1.36 \%$, to the total decoloration of methyl orange on the $\mathrm{TiO}_{2}-\mathrm{SiO}_{2}$ material. The degradation of methyl orange continues with increasing irradiation time. Degradation rates after 0.5 and $2 \mathrm{~h}$ are $31.1 \%$ and $92.9 \%$. The two main absorption peaks of methyl orange at $468 \mathrm{~nm}$ and $270 \mathrm{~nm}$ decline with increasing reaction time.
\end{abstract}

Keywords: $\mathrm{TiO}_{2}, \mathrm{SiO}_{2}$, Photocatalysis, Methyl orange.

\section{INTRODUCTION}

The treatment of organic pollutants in the environment is always research focus among which photocatalytic oxidation has grown to be an interesting method ${ }^{1,2}$. The widely studied $\mathrm{TiO}_{2}$ is believed to be a satisfactory material because of its high activity and other advantages ${ }^{3-6}$. In order to promote the activity of pure $\mathrm{TiO}_{2}$, composite materials were prepared including the composition of $\mathrm{TiO}_{2}$ and other oxides, such as $\mathrm{SiO}_{2}{ }^{7}$, $\mathrm{ZrO}_{2}{ }^{8}, \mathrm{WO}_{3}{ }^{9}, \mathrm{Cu}_{2} \mathrm{O}^{10}$ and $\mathrm{Ta}_{2} \mathrm{O}_{5}{ }^{11}$. We firstly published a paper recently in reporting one-step sol-gel method to prepare porous $\mathrm{TiO}_{2}-\mathrm{Al}_{2} \mathrm{O}_{3}$ composite photocatalyst ${ }^{12}$.

In this paper, a $\mathrm{SiO}_{2}-\mathrm{TiO}_{2}$ photocatalyst was prepared through sol-gel method for photocatalytic degradation of methyl orange. The materials were characterized by X-ray diffraction (XRD), scanning electron microscope (SEM), frontier transform infrared spectrophotometer (FT-IR) and $\mathrm{N}_{2^{-}}$ adsorption and desorption techniques. Photocatalytic activity of the materials was also investigated for degradation of methyl orange.

\section{EXPERIMENTAL}

The $\mathrm{SiO}_{2}-\mathrm{TiO}_{2}$ catalyst was prepared according to a solgel process by the following method. Tetrabutyl titanate $\left[\mathrm{Ti}(\mathrm{OBu})_{4}, 2 \mathrm{~mL}\right]$ and ethyl silicate $(0.0075 \mathrm{~mL})$ were slowly added to ethanol under continuous magnetic stirring to obtain a mixed slurry. Another ethanol-water solution was added to the mixed slurry to hydrolyze tetrabutyl titanate and ethyl silicate after the mixture was stirred for $1 \mathrm{~h}$. The molar $\mathrm{Si} / \mathrm{Ti}$ ratio in the fianl precursor was 0.003 and $\mathrm{V}\left[\mathrm{Ti}\left(\mathrm{OC}_{4} \mathrm{H}_{9}\right)_{4}\right]$ : $\mathrm{V}\left(\mathrm{C}_{2} \mathrm{H}_{5} \mathrm{OH}\right): \mathrm{V}\left(\mathrm{H}_{2} \mathrm{O}\right): \mathrm{V}(\mathrm{HCl})=1: 5: 0.5: 0.05$. The resulting slurry was still under continuous magnetic stirring until it became a gel. The gel was dried at $80{ }^{\circ} \mathrm{C}$ for $8 \mathrm{~h}$ and calcined at $500{ }^{\circ} \mathrm{C}$ for $3 \mathrm{~h}$. Finally, the catalysts were grinded into fine powders and stored in the dark.

Characterization: Scanning electron microscope (SEM) image was taken on a HTACHI S-3400N scanning electron microanalyzer. The sample for SEM imaging was coated with a thin layer of gold film to avoid charging. The crystalline phase of the photocatalyst was measured by X-ray diffraction (XRD) with $\mathrm{D} / \mathrm{max}-\mathrm{rB}$ diffractometer using a $\mathrm{CuK}_{\alpha}$ radiation. FT-IR spectrum of the sample was recorded using a FT-IR spectrometer in the wavenumber range of $4000-400 \mathrm{~cm}^{-1}$. The $\mathrm{N}_{2-}$ adsorption and desorption of the sample was measured by $\mathrm{F}$ Sorb 3400 specific surface area and pore size distribution analytical instrument. Specific surface area and pore size distribution were calculated from the $\mathrm{N}_{2}$ desorption isotherms, according to Brunauer-emmett-teller (BET) equation and Barrett-joyner-halenda (BJH) method, respectively.

Photocatalytic activity: Photocatalytic activity of the photocatalyst was evaluated by measuring degradation rate of aqueous methyl orange under UV irradiation. In each experiment, $0.03 \mathrm{~g}$ of the photocatalyst was put into $50 \mathrm{~mL}$ of 10 $\mathrm{mg} / \mathrm{L}$ aqueous solution of methyl orange in a $200 \mathrm{~mL}$ beaker. 
A $20 \mathrm{~W}$ UV lamp was suspended $11 \mathrm{~cm}$ above the solution. The lamp can irradiate UV light at wavelength of $253.7 \mathrm{~nm}$ with the intensity of $1100 \mathrm{~mW} / \mathrm{cm}^{2}$. In prior to turn on the lamp, the solution was magnetically stirred for $30 \mathrm{~min}$ to ensure adsorption equilibrium. Methyl orange concentration was measured by a spectrophotometer (Shanghai spectrum instruments 721E) at its maximum adsorption wavelength of $466 \mathrm{~nm}$. The suspensions were filtered through a Millipore filter (pore size $0.45 \mathrm{~mm}$ ) before measuring. Irradiation time in the subsequent experiments was $0.5 \mathrm{~h}$ except for the prolonged examination.

\section{RESULTS AND DISCUSSION}

Transition metal doping and composite photocatalyst have been used to enhance the activity of $\mathrm{TiO}_{2}$ containing materials. Sol-gel is a widely applied method used for preparation of nano-sized $\mathrm{TiO}_{2}$ photocatalyst. The introducing of $\mathrm{SiO}_{2}$ can effectively enhance crystalline structure of $\mathrm{TiO}_{2}$, inhibit phase transform from anatase to rutile and therefore promote photocatalytic activity.

Fig. 1 shows XRD pattern of $\mathrm{TiO}_{2}-\mathrm{SiO}_{2}$ composite material which was calcinated at $500{ }^{\circ} \mathrm{C}$ for $3 \mathrm{~h}$. The diffraction peaks of (101), (004) and (200) planes are in accordance to standard anatase $\mathrm{TiO}_{2}$. There is no apparent diffraction peak corresponding to rutile $\mathrm{TiO}_{2}$ or brukite $\mathrm{TiO}_{2}$. Meanwhile, there is no diffraction peak corresponding to crystalline $\mathrm{SiO}_{2}$. The material is composed of anatase $\mathrm{TiO}_{2}$ and most probably amorphous $\mathrm{SiO}_{2}$. The crystallite size of the (101) plane is $14.39 \mathrm{~nm}$, calculating using Scherrer formula.

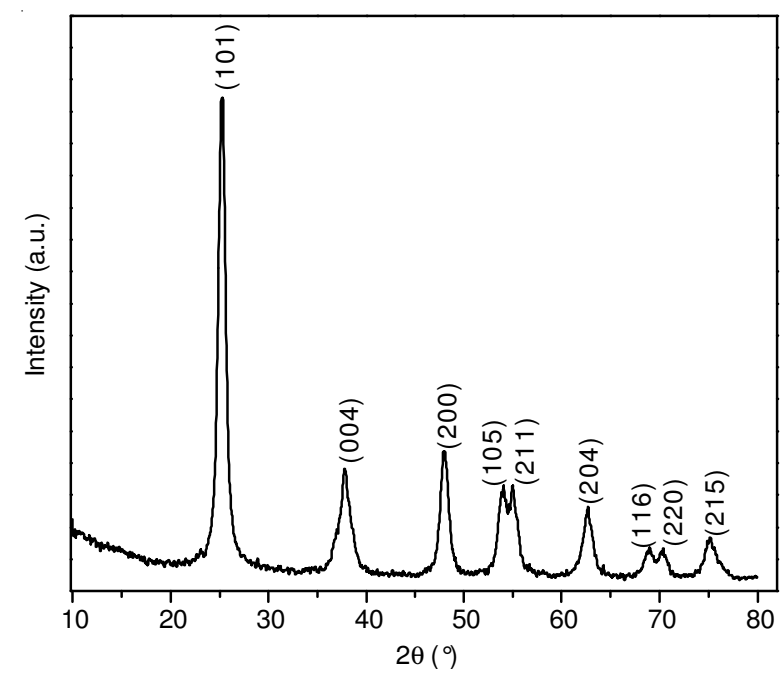

Fig. 1. XRD pattern of $\mathrm{TiO}_{2}-\mathrm{SiO}_{2}$ composite material

SEM image of $\mathrm{TiO}_{2}-\mathrm{SiO}_{2}$ composite material is shown in Fig. 2. The surface of the sample is fairly rough. Some particles in the size smaller than $1000 \mathrm{~nm}$ scatter on the surface. These small particles might be produced during grinding and be adsorbed on the surface.

FT-IR spectrum of $\mathrm{TiO}_{2}-\mathrm{SiO}_{2}$ composite material is shown in Fig. 3. The low-frequency absorption band at $466 \mathrm{~cm}^{-1}$ is attributed to the Ti-O-Ti vibration of the samples. The band at $1625 \mathrm{~cm}^{-1}$ corresponds to the bending vibration of $\mathrm{O}-\mathrm{H}$ and the band around $3416 \mathrm{~cm}^{-1}$ is assigned to the surface adsorbed water and hydroxyl groups. That means some $\mathrm{H}_{2} \mathrm{O}$ molecules

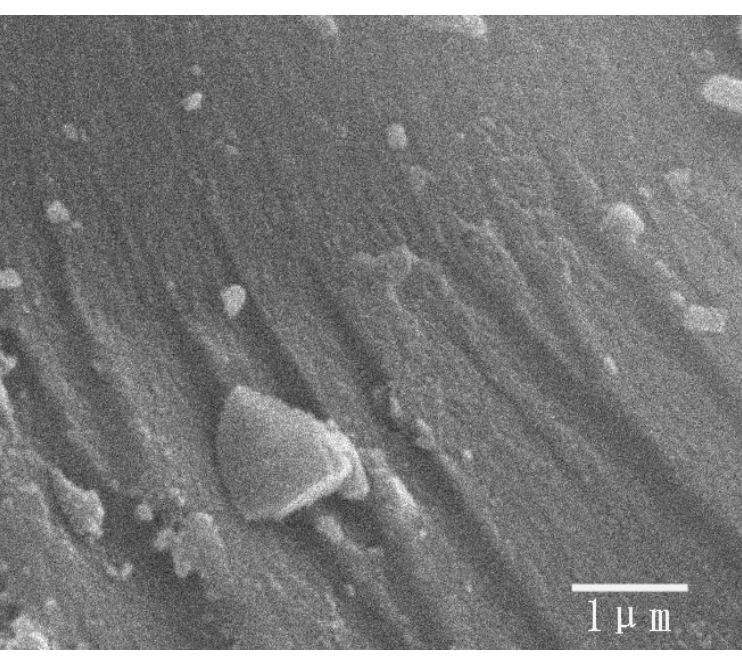

Fig. 2. SEM image of $\mathrm{TiO}_{2}-\mathrm{SiO}_{2}$ composite material

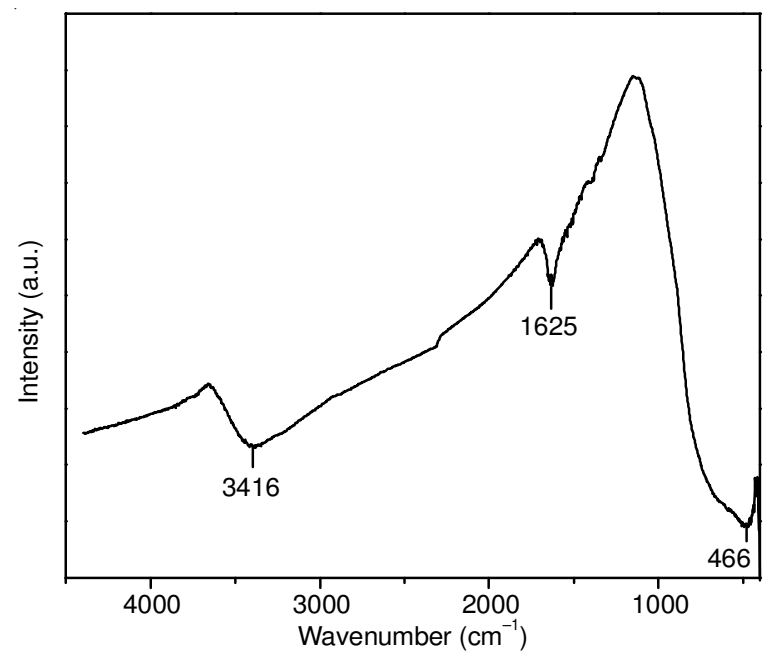

Fig. 3. FT-IR spectrum of $\mathrm{TiO}_{2}-\mathrm{SiO}_{2}$ composite material

are adsorbed on the surface. No clear evidence of Si-O-Si or $\mathrm{Si}-\mathrm{O}-\mathrm{Ti}$ vibration is found in the FT-IR spectra because of the very low concentration of $\mathrm{SiO}_{2}$ in $\mathrm{TiO}_{2}$ matrix.

Fig. 4 presents $\mathrm{N}_{2}$ desorption isotherm and pore size distribution of $\mathrm{TiO}_{2}-\mathrm{SiO}_{2}$ composite. With the increase of relative pressure P/Po in Fig. 4a, the adsorption of $\mathrm{N}_{2}$ on the material amplifies apparently. When the relative pressure $\mathrm{P} / \mathrm{P}_{0}$ is between 0.7 and 0.9 , the increment of adsorption is significant because of capillary condensation of nitrogen molecules in the pores of the material. Fig. 4 b clarifies the mesoporous structures of the material. The pore size of the material is mainly below $15 \mathrm{~nm}$ and the pore diameter mainly distributes in the range from $2 \mathrm{~nm}$ to $11 \mathrm{~nm}$. The material has the maximum pore volume of $0.02935 \mathrm{~cm}^{3} \mathrm{~g}^{-1}$ when pore size is $4.628 \mathrm{~nm}$. The average pore diameter is $13.02 \mathrm{~nm}$ and the total pore volume is $0.2004 \mathrm{~cm}^{3} \mathrm{~g}^{-1}$ along with specific surface area of $61.56 \mathrm{~m}^{2} \mathrm{~g}^{-1}$, as calculated using BJH and BET methods.

The degradation of methyl orange and adsorption on the $\mathrm{TiO}_{2}-\mathrm{SiO}_{2}$ under UV irradiation are shown in Fig. 5. Under magnetic stirring, adsorption reaches its equilibrium in less than $0.5 \mathrm{~h}$. No variation occurs with further increase of adsorption time. Meanwhile, adsorption only contributes a small part, less than $1.36 \%$, to the total decoloration of methyl orange on the $\mathrm{TiO}_{2}-\mathrm{SiO}_{2}$ material. The degradation of methyl orange 

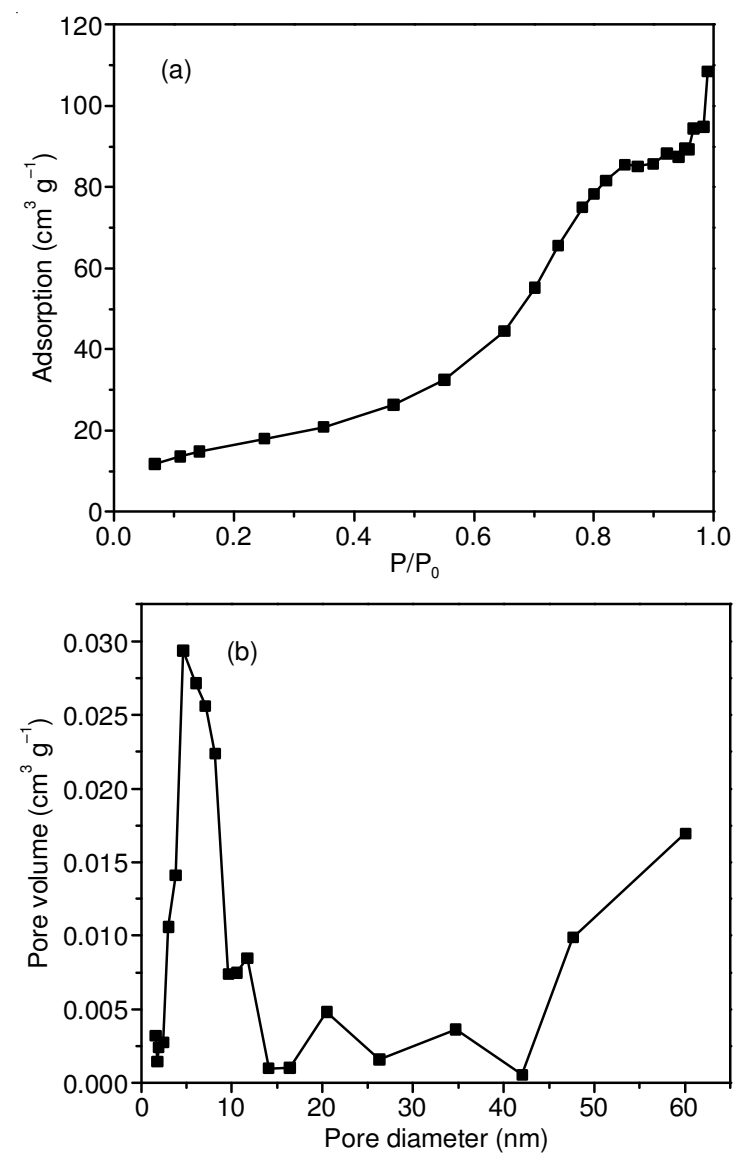

Fig. 4. $\mathrm{N}_{2}$ desorption isotherm (a) and pore size distribution (b) of $\mathrm{TiO}_{2}-\mathrm{SiO}_{2}$ composite

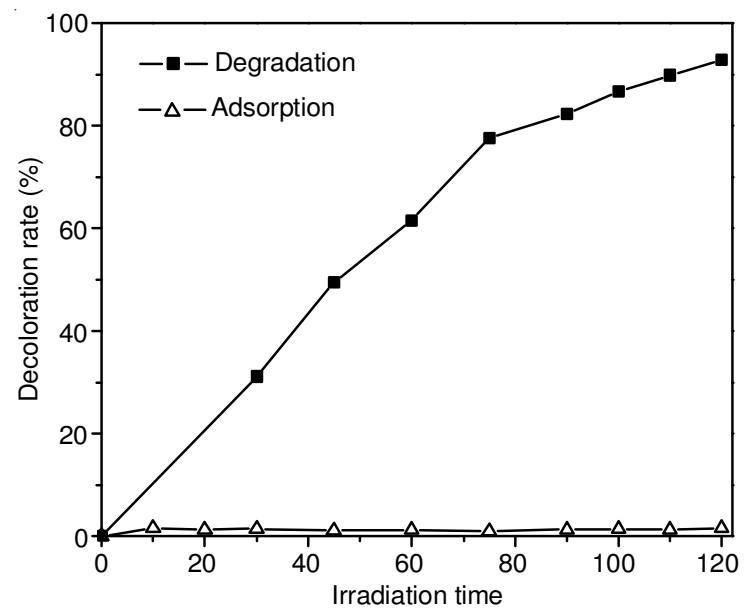

Fig. 5. Effect of irradiation time on decoloration rate of methyl orange

continues with increasing irradiation time. Degradation rates after 0.5 and $2 \mathrm{~h}$ are $31.1 \%$ and $92.9 \%$, respectively. The $100 \%$ decoloration of the dye can be expected with prolonged irradiation time.

UV-visbile absorbance curves of methyl orange solution after different irradiation time are shown in Fig. 6. The two main absorption peaks of methyl orange at $468 \mathrm{~nm}$ and 270 $\mathrm{nm}$ decline with increasing reaction time. The absorbance of the peak at $468 \mathrm{~nm}$ nearly disappears after $4 \mathrm{~h}$ of irradiation. The azo structure in the dye is fully degraded during photocatalytic oxidation process.

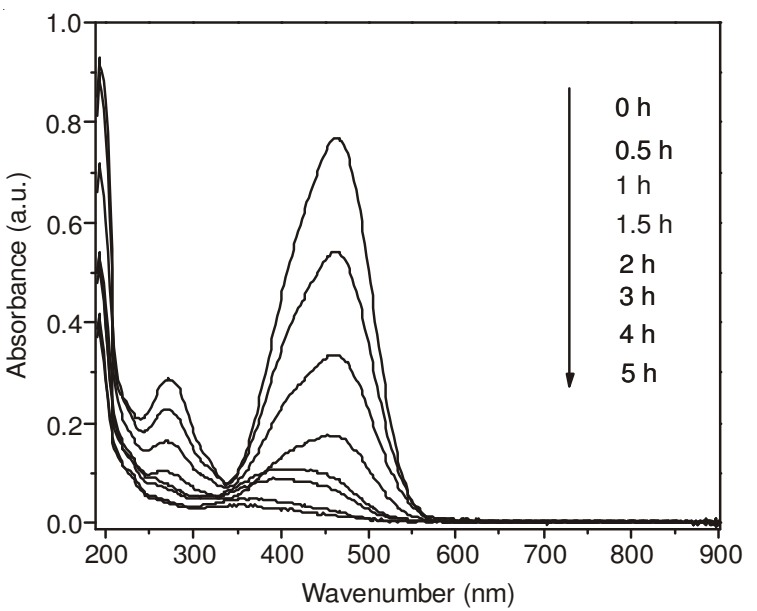

Fig. 6. UV-visible curves of methyl orange after different irradiation time

\section{Conclusion}

A $\mathrm{SiO}_{2}-\mathrm{TiO}_{2}$ photocatalyst was prepared through sol-gel method for photocatalytic degradation of methyl orange. The material is composed of anatase $\mathrm{TiO}_{2}$ and amorphous $\mathrm{SiO}_{2}$. No clear evidence of Si-O-Si or Si-O-Ti vibration is found in the FT-IR spectra because of the low concentration of $\mathrm{SiO}_{2}$ in $\mathrm{TiO}_{2}$ matrix. The average pore diameter is $13.02 \mathrm{~nm}$ and the total pore volume is $0.2004 \mathrm{~cm}^{3} \mathrm{~g}^{-1}$ along with specific surface area of $61.56 \mathrm{~m}^{2} \mathrm{~g}^{-1}$. Methyl orange degradation continues with increasing irradiation time. The azo structure in the dye is fully degraded during photocatalytic oxidation process.

\section{ACKNOWLEDGEMENTS}

This work was supported by the National Natural Science Foundation of China (No. 41271251) and the Open Research fund of Key Laboratory of Wastewater Treatment Technology of Liaoning Province, Shenyang Ligong University.

\section{REFERENCES}

1. D. Chatterjee and S. Dasgupta, J. Photochem. Photobiol. Chem., 6, 186 (2005).

2. A. Fujishima, T.N. Rao and D.A. Tryk, J. Photochem. Photobiol. Chem. $C, \mathbf{1}, 1$ (2000).

3. M.I. Litter, Appl. Catal. B, 23, 89 (1999).

4. Q.Y. Li, K. Wang, S.L. Zhang, M. Zhang, J.J. Yang and Z.S. Jin, J. Mol. Catal. A, 258, 83 (2006).

5. H.M. Sung-Suh, J.R. Choi, H.J. Hah, S.M. Koo and Y.C. Bae, J. Photochem. Photobiol. A, 163, 37 (2004).

6. W.C. Hung, Y.C. Chen, H. Chu and T.K. Tseng, Appl. Surf. Sci., 255, 2205 (2008).

7. J.X. Jiao, Q. Xu and L. Li, J. Colloid Interf. Sci., 316, 596 (2007).

8. B. Neppolian, Q.L. Wang, H. Yamashita and H. Choi, Appl. Catal. A, 333, 264 (2007).

9. M.R. Bayati, A.Z. Moshfegh, F. Golestani-Fard and R. Molaei, Mater. Chem. Phys., 124, 203 (2010).

10. X.D. Su, J.Z. Zhao, Y.L. Li, Y.C. Zhu, X.K. Ma, F. Sun and Z.C. Wang, Colloids Surf. A, 349, 151 (2009).

11. M. Stodolny and M. Laniecki, Catal. Today, 142, 314 (2009).

12. W.J. Zhang, R.Y. Li and B. Yang, Nanosci. Nanotechnol.-Asia, 2, 59 (2012). 